\title{
7 Homestuck as a game
}

\author{
A webcomic between playful \\ participation, digital technostalgia, \\ and irritating inventory systems
}

\section{Tim Glaser}

Homestuck is a webcomic of truly epic proportions. Created by Andrew Hussie between 2009 and 2016, it consists of over 8,000 pages and contains various media formats. It has been called the "Ulysses of the Internet" (PBS Idea Channel 2012) and "a genre-fusing postmodern epic designed for and produced through the internet" (Litwhiler 2013, 1). As the creator himself put it: Homestuck is "a story about kids on the internet, that is told in a way that is like, made of pure internet" (O'Malley 2012, n.p., original emphasis). However, Homestuck not only utilizes the possibilities of digital production and reception, but the narration, style, and collaboration are themselves influenced by characteristics of digital media, especially game mechanics, obsolete technology, and playful interaction. For instance, the protagonists have to obey specific rules, such as a needlessly elaborate inventory system or leveling for inanimate objects, while simultaneously playing Sburb, a dangerous sandbox game that is superimposed over their real world. Furthermore, the first three chapters of Homestuck were created on the basis of various suggestions by readers, enabling them to directly participate in the game's gestation (Short 2014, 45).

This chapter argues that Homestuck is not only influenced by videogames and genre conventions, but that the webcomic can be understood as a playful yet critical appraisal of various aspects of gaming culture, digital technology, and fandom. Analyzing the interconnections between ludic, graphic, and narrative elements in this multilayered universe, which seems to be converging and diverging simultaneously, enables us to reflect on the interactions between metamedia elements and different modes of engagement. Hence, this chapter will first provide a very brief introduction to Homestuck and its story, production, and reception. The second section will focus on theories of metamedia storytelling and technostalgia and on their relation to webcomics and indie games. Finally, I analyze Homestuck as a game, with a focus on readers as players and references to gaming culture, tropes, and genres. The aim of this chapter is to demonstrate how Homestuck uses these different elements to encapsulate and reflect on the process of growing up in the age of online communities and digital communication. 


\section{Welcome to Homestuck}

Homestuck is foremost a digital webcomic ${ }^{1}$ created by Andrew Hussie, with assistance by various collaborators and fans who contributed pieces of music, artwork, ideas, and feedback. ${ }^{2}$ The first page of Homestuck-not considering a short alpha run-was posted on 13 April 2009. Homestuck ran for seven years, and the official credits were posted on 25 October 2016. ${ }^{3}$ On 13 April 2019-ten years after the initial start-a written epilogue to the webcomic was uploaded to the main page that also paid homage to self-hosted fan-fiction website Archive of Our Own, and in the same year Homestuck 2: Beyond Canon was released as an official sequel. ${ }^{4}$ Beyond being a webcomic, Homestuck utilizes a range of digital media formats, everything from drawn images, animated GIFs, and chat logs to Flash animations, mini-games, and video files. In its entirety, Homestuck includes more than 8,000 pages, four hours of animation, and 800,000 words (Bailey 2018).

Homestuck was Hussie's fourth entry in the so-called MS Paint Adventures series, ${ }^{5}$ after Problem Sleuth (2008-2009), Bard Quest (2007), and Jailbreak (2006-2007, 2011). All of them share the visual and logical imitation of old parser-based adventure games, while their plot development was shaped by audience participation via text-based inputs: "Hussie encouraged fans to share his role as author, allowing them to feel a sense of ownership and investment in the story" (Short 2014, 46). The "players" (readers and collaborators) suggest actions for the characters in the diegesis to performsimilar to commands typed into text prompts of adventure games. Hussie in turn chose a suggestion for the next panel. Primarily relying on a simple stick-figure style, Hussie was able to draw proposed actions quickly and could publish several panels per day. ${ }^{6}$

The narrative of Homestuck revolves around the friendship between and adventures of four thirteen-year-olds: John Egbert, Rose Lalonde, Dave Strider, and Jade Harley_respectively also known by their online handles ectoBiologist, tentacleTherapist, turntechGodhead, and gardenGnostic. While playing the immersive simulation sandbox game Sburb, a meteor shower appears and threatens to destroy planet earth. Before this happens, the game provides these teenagers with a complex alchemy system, an in-game collecting and crafting mechanic, to escape. Succeeding in this challenge transports them to a dimension called the "Medium." Advancing further, the four friends learn that Sburb was a mechanism designed to create a new universe. And the meteor shower and subsequent destruction of earth was initiated through the game and future versions of themselves. Many other important figures exist, such as the humanoid aliens called trolls (who also play a version of the game called Sgrub), guardian characters, clones, and the nonplayer character Lord English, who runs amok and threatens the protagonists. 
Considering its scope and complexity, Homestuck appears to be an epic saga, including seemingly never-ending battles between good and evil, with the fate of the world at stake. Additionally, it incorporates tropes of fantasy, science-fiction, and horror genres, such as alien races, time traveling, strange artifacts, monsters, and mayhem. But beyond mere genre references, Homestuck oscillates between ironic dissociation and a serious examination of adolescence. Metaphors for growing up and elements from young adult fiction can be seen in the teenage protagonists and the focus on quirky internet friendship, shared memes, in-group jokes, awkwardness, and romance. In that sense, the emphasis of Homestuck lies on the experience of the characters - the kids and trolls_-and their relationships among each other, and to their siblings and parents. This focus is echoed in the discourse and practices of the Homestuck fandom on questions of identity, LGBTIQthemes and characters, especially in relation to the aforementioned trolls. ${ }^{7}$

These and other aspects of fandom were important factors for making Homestuck not only popular, but relevant. While the webcomic itself alluded to various aspects of geek, nerd, media, and internet cultures at large, the fan following "took over" this interconnected network of references and enhanced it through the usage of memes, running gags, Tumblr pages, fan art, fan fiction, and cosplay-and thus transformed the webcomic into a multifaceted participatory space. ${ }^{8}$ With this in mind, it is important to understand that the "phenomenon" of Homestuck and the webcomic itself cannot be separated, especially since many of Hussie's design and story choices were influenced by readers, fans, and players. Therefore, this chapter addresses only a relatively small slice of Homestuck and the community experience it enabled. I will focus on the first three acts of Homestuck, including the webcomic, as well as interviews and paratexts written by Hussie. I will emphasize the relations between media, technology, and (web)comics as they relate to the concept of technostalgia and to modes of engagement. In addition, I will analyze the influence of videogame logic and tropes on Homestuck as well as different instances of interactivity, participation, and playfulness.

\section{Forensic fandom and technostalgia in Homestuck}

Homestuck's network of media formats, references, and genre tropes can be interconnected through what Kevin Veale names "metamedia storytelling," which he describes as "a technique where the audience's pre-existing and intuitive familiarity with modes of engagement from the wider landscape of mediated storytelling is used as a tool to shape and manipulate their experience of the text" $(2019,1029)$. Considering Homestuck, these different modes of engagement include-but are not limited to-webcomic, written fiction (and metafiction), animation (Flash, video, and GIF), puzzle solving, interactive (mini-)games, and other forms of participation. According to Veale, this multitude of modes and media formats, references, and literacies 
can be linked to the concept of "forensic fandom" (Mittell 2007), where the audience-the "players"-needs a detective mentality to engage with the comic, texts, and other media formats. This notion is echoed in Hussie's own description: "The thing is, Homestuck is both a story and a puzzle, by design and by definition. [...] There is a range of ways to interface with it, from the casual to the maniacal. Failing to grasp everything shouldn't preclude basic enjoyment, nor is it a symptom of failure by either the reader or the story" (Hussie 2014, n.p.). Those various modes of reception, forms of remediation, and different media elements expand on what can be understood as the media specificity ${ }^{9}$ of (web)comics. This can be retraced in the way Homestuck reflects on media history, since outdated and obsolete digital technology and web-based media play an important part in the narration.

The relationship between personal history, generations, nostalgia, and media has been discussed by Göran Bolin, who concludes that technology is important for discussing the feeling of lost childhood and the desire to mediate intergenerational experience. In this context, Bolin introduces the term "technostalgia" $(2016,256)$ to describe a specific longing for outdated technology that is bound to devices and practices like analogue media and outdated communication forms. This longing can include technology as artifacts as well as the investment of personal struggle, time, and labor. One example would be the yearning for a "pre-digital connectedness that precedes contemporary social networking media" (Bolin 2016, 256). Homestuck, which started 2009, emerged during the reign of platformbased social media monopolies. ${ }^{10}$ But contrary to these monopolies, the diegesis of and the references in Homestuck rely on technostalgic media and outdated "web 1.0" technology.

Technonostalgia appears most notably in the integration of various instant messaging systems as the primary medium for communication. This focus combines the sincere retelling of making friends in networked communities with poking fun at the limitations and peculiarities of this mode of communication. The conversations of the kids almost exclusively take place via Pesterchum ${ }^{11}$ (see Figure 7.1). Using their different online handlescalled Chumhandles - the kids converse not via speech bubbles but through a Pesterlog, which is placed on the page under the comics panel. The use of a chatlog changes the way the comic is read by utilizing the various media formats, such as the difference between animated panels and written text. The communication tends to be more extensive since the length of the Pesterlogs is not limited by the size of the panels.

Regarding aesthetics and practice, the design of Pesterchum resembles more outdated instant messaging services, such as ICQ, MSN, or AOL Instant Messenger, which were all created between 1995 and 1997 and shaped early communication on the internet (see Figure 7.1). The technostalgia element is not linked to an analogue area of social interaction but to a less centralized mode of communication, not bound to platforms and algorithmic optimization of content and advertisement. At the same time, the characters can 


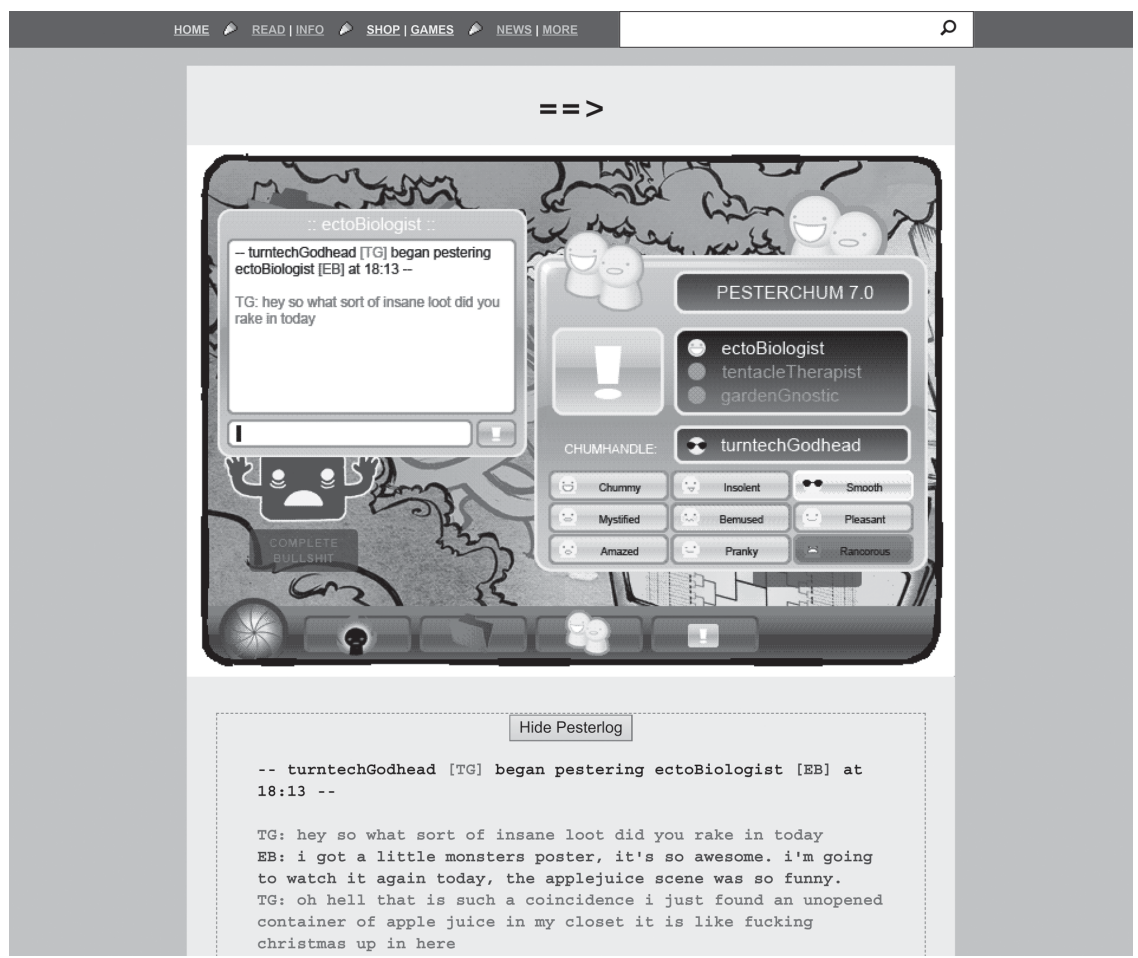

Figure 7.1 “-- turntechGodhead [TG] began pestering ectoBiologist [EB] at 18:13 --” (Hussie 2018, 324). (C) Homestuck and VIZ Media.

only express their individuality with their username, text color, and writing quirks.

This examination of early-twenty-first-century digital communication was also the starting point for several recent indie games, ${ }^{12}$ which also remediated lost modes of communication and vacant online spaces. ${ }^{13}$ One example is Emily Is Away (2015) developed by Kyle Seeley. The interactive visual novel tells the story of an unnamed protagonist and his relationship to Emily. Using a retro chat client interface, the game tells a (mostly linear) story, but the player is also able to change icons, profile information, and text color to fit the aesthetic style of the early-to-mid 2000s. As Julie Muncy described it in her review, Emily Is Away is "a game that conjures nostalgia for the pre-social media days of overwrought away messages and grating sound effects. It's a simulated conversation, a chat bot with the structure of an adventure game" (Muncy 2015, n.p.).

Nina Freeman's work is also linked to recreating lost media experiences, with a focus on personal history, fandom, and gaming. Lost Memories Dot Net (2017), for example, is a self-described "game about teen girls, 
blogs and love triangles in 2004" and was created for the Manchester International Festival in 2017. ${ }^{14}$ Two years prior, she had released Cibele (2015), which fused personal experience, photography, a simulated desktop, and a remediated MMORPG. This can be understood as an interactive and mediate form of technostalgia, or, as Chartrand and Thériault describe it, as a blending of different virtual worlds: "[T] he game [Cibele] explores the creator's memories via a virtual world, which is a representation of the one in which she herself has lived these experiences" $(2018,7) .{ }^{15}$

These games shed some light on the relation between the internet as a timeless technology and certain practices of communication and representation that feel outmoded. Olia Lialina describes the lost amateur web of the 1990s as a vernacular web: "[I]t was bright, rich, personal, slow and under construction. It was a web of sudden connections and personal links. Pages were built on the edge of tomorrow, full of hope for a faster connection and a more powerful computer" (2015, n.p.). ${ }^{16}$ Homestuck's involvement in technostalgia also fuses the individual experiences of readers with different real and fictionalized media histories and modified versions of obsolete or outmoded technologies.

Pesterchum appears as a mimicry of early 2000s chat clients, but other references are more direct. Rose's first search for information on Sburb leads her to GameFAQs, ${ }^{17}$ and later she writes her own walkthrough on the platform (Hussie 2018, 249). ${ }^{18}$ While her walkthrough functions as a summary of the first act, it also appears on the extradiegetic page as "Sburb Beta Walkthrough," filed under the Simulation "Virtual " Virtual Life genre, connecting the fictionalized and the real digital spaces. Dave uses blogspot. com to host his "sweet bro's hella blog," ${ }^{19}$ where he reviews the latest issue of the gaming magazine GameBro, ${ }^{20}$ among other things. Another reference is the intradiegetic webcomic "Sweet Bro and Hella Jeff," also created by Dave and read by the other three earthling protagonists. ${ }^{21}$ Spanning 46 episodes, this webcomic features not only absurd storylines in the style of a nightmare-inducing GIF and glitch chaos, but it functions as a distorting mirror for various plot developments.

Finally, the webcomic Homestuck itself is facing forms of media loss and soon-to-be technostalgia. In 2017, the software company Adobe Inc. declared the end of life of Adobe Flash when they announced that they would "stop updating and distributing the Flash Player at the end of 2020" (Adobe Corporate Communications 2017, n.p.). Mozilla had already deactivated Flash plugin for the popular Firefox Browser. This affected various interactive elements in Homestuck. In the current version, most minigames have been replaced by images describing the experience-resembling a strategy guide. $^{22}$ This affects story-driven minigames, such as the point-and-click adventure in which John explores his house (Hussie 2018, 253) as well as smaller games, such as Jade playing her flute (Hussie 2018, 769). In addition, part of the MS Paint Adventures forums were lost, since during a server transfer data was corrupted. ${ }^{23}$ While Homestuck lost an important element 


\section{T. Glaser}

of interactivity and playfulness through this change in technology, there is still a lot of game left. Reading Homestuck as a game in the next segment does not imply that Homestuck is a game, ${ }^{24}$ but that specific tropes, ideas, and modes of reception have game-like elements and, as such, reflect on our notion and understanding of game rules, genres, and tropes.

\section{Homestuck as a game}

A young man stands in his bedroom. It just so happens that today, the 13th of April, 2009, is this young man's birthday. Though it was thirteen years ago he was given life, it is only today he will be given a name!

(Hussie 2018, 1)

The first page of Homestuck starts with an opening that resembles the first interaction in many role-playing adventures: the naming of the protagonist (see Figure 7.2). This particular element of videogame logic is not only employed to draw the audience in but is ironically called upon in the accompanying text. With his thick glasses-and without hands-the unnamed young man is standing in front of a door, next to a cake. He is apparently waiting for a player input.

Observing the first page one notices that the first panel of Homestuck is not a still image, but an animation, a looping GIF animation to be exact. ${ }^{25}$ The minor and repetitive movements of the yet unnamed young man might remind the audience of another videogame trope, the idling animation. Those mostly small, sometimes funny movements that happen "when a player leaves a game alone for a bit, are easy to overlook but key to conveying subtle (or not-so-subtle) aspects" (Couture 2018, n.p.) of videogames, their world, and their atmosphere. Galloway differentiates between different modes in videogames: " $[\mathrm{M}]$ achine actions are acts performed by the software and hardware of the game computer, while operator actions are acts performed by players" (Galloway 2006, 5). Even though this separation is "completely artificial-both the machine and the operator work together in a cybernetic relationship" (Galloway 2006, 5), the resemblance of "machine actions" reminds us of the world as a purposefully designed environment, waiting for our operator actions.

On the first page of Homestuck, the question, "What will the name of this young man be?" is central. Homestuck gives the player/reader only one option for an operator action: "> Enter name." The greater-than sign $>$ refers to the aforementioned parser-based text games with the $>$ signaling user input in the style of imperative commands. ${ }^{26}$ Clicking on the "> Enter name." prompt brings players to the second page of Homestuck. Here, another GIF animation is looping, displaying the typing of "Zoosmell Pooplord," which prompts a negative reaction from the yet to be named character and a "try again, smartass" tool tip (Hussie 2018, 2). Something prevents this juvenile joke, or maybe the character demonstrates his own agency. Fortunately, 


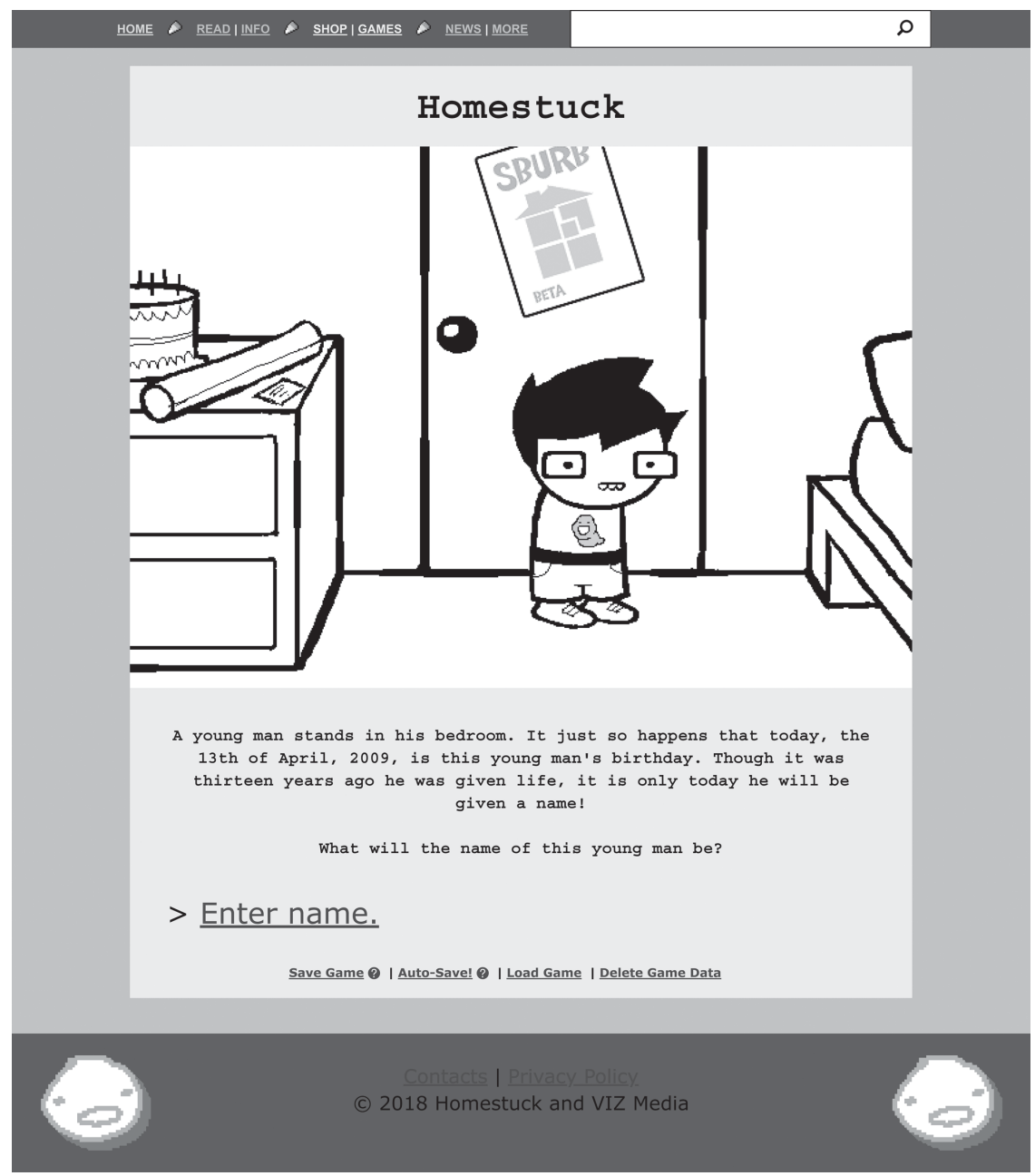

Figure 7.2 "Homestuck > Enter name." (Hussie 2018, 1). (C) Homestuck and VIZ Media.

the prompt on the second page enables the possibility for a revision: "> Try again." This leads to the third page, and the second suggestion "John Egbert" results in a smile by John and gets a green check (Hussie 2018, 3). The community successful named the first protagonist of Homestuck. ${ }^{27}$ This all happened 2009, and we can only retrace those actions:

Readers on the internet would suggest an action they wanted a character to take, and I would choose one from the pile and illustrate the results. All of book one [containing act 1 of the webcomic] was created 
this way, as will a number of books following it. You'll find this method generates quite the garden path through a story, leading to a good deal of meandering, silly diversions, gags, trial and error from the "player," and impromptu story crafting decisions. I am playing the role of a dungeon master, a game engine responding to input, and an improv comic all in one.

(Hussie 2011, n.p.)

Homestuck, as noted, was Hussie's fourth webcomic in the MS Paint Adventures series, based on quick production and the possibility to participate. The first three acts of Homestuck were mostly written by using this suggestion-based system. In 2010 Hussie locked the suggestion boxes while he crafted longer story arcs, and the influence became more indirectpresent through polls, forum entries, fan art, or other fan creations. One example is the naming of characters, for which Hussie used the MS Paint Adventures forums to gather recommendations. Another tool was online polls, for example, to conclude the outcome to the "WARDROBIFIER'S randomization mode" (Hussie 2018, 800), which automatically changes the symbol on Jade's shirt. ${ }^{28}$ Homestuck evolved from a system that resembled a community-based let's play comic, in which the characters were under a chaotic hivemind control of the audience, to a more mediated approach, in which the creator and fans construct a world together and see which narrative possibilities emerge from the different elements.

Beyond the initial naming of the protagonist, Homestuck features more references to videogame culture. The whole world in which the four teenagers live functions according to rules that resemble well-known conventions of game genres, especially role-playing and adventure games: a leveling system, currencies, fighting system, and inventory management, to mention a few. Especially in the first chapters, those systems are paramount since these chapters act as the introduction, both for the readers/players and children. "This is common logic in game tutorials, where characters straddle postmodern awareness of the game mechanics on which they directly or indirectly seek to educate you, as well as themselves, strangely" (Hussie 2011, 6).

As with other elements of the webcomic, these gaming mechanics are mainly used to poke fun at existing tropes. For example, the leveling system is constructed around silly names and abstract numerical values. John starts with Greentike and levels up to Anklebiter, Pesky Urchin, and so forth..$^{29}$ The "Level up!" also provides Boondollars and upgrades such as "Gel Viscosity" or "Man Grit," thus overloading the readers with-seldom useful, mostly absurd-detailed information. Furthermore, inanimate objects, such as refrigerators or bathtubs (Hussie 2018, 557), can level up.

Sylladices are another nuisance for the four protagonists. Every kid has their own inventory system, with a spin on the classic management system popularized by point-and-click adventures. Referring to both syllabus and index, each Sylladex has a specific fetch mode that determines how 
artifacts—represented as captchalogued cards—are stored and retrieved. The different available modes refer to common data structures, board games, or other sorting systems. John starts with a Sylladex representing a stack, with only the option to interact with the card on top of his stack. Later he acquires the queue and array modes, which he combines to a queuestack array, enabling him to carry 24 cards at the same time and switching between accessing the top or bottom card of his six arrays. ${ }^{30}$ His friends also use difficult-tointeract systems. Rose employs a tree fetch mode, which uses a binary system to store new cards on branches. ${ }^{31}$ Board games, such as Memory, Jenga, or Pictionary, are the base for Jade's twelve fetch modes, and the hash map fetch mode that Dave uses can contain ten cards, with values ranging from 0 to 9 (Hussie 2018, 319). For Dave, every artifact that is captchalogued gets its hash value calculated, based on "valuing each consonant at 2 , and each vowel at 1" (Hussie 2018, 319). Beyond that, each item can only be retrieved by an action with the same index value-which leads to accidents. At one time, Dave ejects his sword by yelling "stop" at a bird, killing the bird in the process. ${ }^{32}$ As Hussie notes, those complicated Sylladices are part of a playful approach to videogames and interactivity: "Carefully educating you on needlessly complicated inventory systems that eventually get retired from a game you never get to play that doesn't actually exist. HOMESTUCK" (Hussie 2011, 10).

Superimposed over their world, the videogame Sburb becomes the point of departure for the main story arc. Playing Sburb starts the apocalypse and subsequent destruction of the earth, but it also provides the possibility to create a new reality. Sburb itself is best described as a multiplayer sandboxstyle game with elements taken from building and simulation games. After a client player and server player connect, the server player can manipulate, create, and destroy objects in real time. ${ }^{33}$ Using different obscure crafting material, such as numerous versions of Grist, artifacts can be constructed with which the client player can interact. This creates a multilayered world where different ludic systems interact and contradict each other. The Sims (2000) was an important inspiration for the mechanics and aesthetic of Sburb, as Hussie $(2011,105)$ himself notes. This can be seen in the isometric perspective, which itself mediates a specific set of genre expectations. Additionally, Hussie built a mock-up interactive menu for Sburb (Hussie $2018,138)$ for the readers to play around with in order to convey the possibility of Sburb being a real game. ${ }^{34}$ Those different levels of reference helped to manage different aspects of expectations and game-specific modes of reception. Furthermore, videogames-including tropes, participation, and genres-shaped the metamedia storytelling and development of Homestuck.

\section{Conclusion}

There are a few moments in the earlier acts which seem to trick you into thinking Homestuck is all about getting cool gear, gaining levels, 
and kicking ass like you except to do in such games. This is kind of misleading though. In totality, HS isn't really about ass-kicking at all. It's about presenting awesome fantasy environments and situations in which ass-kicking could THEORETICALLY take place, but very rarely does except in dramatic hot points like this. Instead, those environments serve as backdrops for a huge amount of dicking around on the internet, babbling to friends about feelings, and being a bunch of stupid useless kids struggling to grow up. If you are ever under the impression HS is about anything else, you are invariably in for a world of hurt.

(Hussie 2013, 257)

This statement underscores Hussie's playful approach to the limitations and capabilities of webcomics and videogames. Instead of creating a hybrid or hypermedium, Hussie relied on addressing themes such as obsolete technology and coming of age by utilizing media literacy, genre expectations, and audience participation. The "metamedia storytelling" of Homestuckbetween technostalgia and community experience-uses videogames as material, discourse, and eventually to expand the understanding of what webcomics are and how they might evolve in the future. Homestuck demonstrates the illusion of a fully interactive experience, of a grand underlying logical system—as Chute and Jagoda summarize, Homestuck "repeatedly frustrates the user's desire for explicit interactivity, inviting and then curbing the type of agency promised by many new media projects" $(2014,10)$.

This frustration and the overall nonpersistence of mechanics, rules, and narrative elements contrasts with a long history of defining videogames as predictable rule-based systems that can be dismantled and theory-crafted. For instance, in Homestuck, countless rules are explained in detail, then soon forgotten or brought back in altered form-may it be the leveling system of inanimate objects or various currencies and building materials. In his book The Toxic Meritocracy of Video Games (2018), Christopher A. Paul describes the influence of merit on videogame narratives: "The story many games tell players is that if you work hard enough, if you are good enough, you can follow a straightforward path to power, wealth, and resources" $(2018,6)$. Homestuck is not only far away from a tale based on merit, but the webcomic also provides an example of gaming and gaming culture that is more than various forms of operator and machine action, input and output, winning and losing. Homestuck emphasizes the absurd and funny side of gaming tropes, such as the act of naming a character when he is already thirteen years old or almost-impossible-to-navigate inventory systems. In remediating the perspectives, aesthetics, and rules taken from different genres-from simulation, role-playing, and parserbased adventure games-it creates a world that is inventive and open-ended. The challenge of questioning videogame conventions, in particular meritocratic ideas, has been echoed in recent years by various indie games. We 
can therefore conclude that the similarities between Homestuck and games such as Cibele and Emily is Away go beyond remediating interfaces and seemingly lost digital communities as they altogether reflect on and criticize cultural assumptions on web-based communication and (sub)cultures. In Homestuck, communication and relationships between the main characters are based around real and fictionalized technostalgia media, creating a community in the diegesis and outside of it and demonstrating that playing together creates social spaces-both in world-destroying multiplayer sandbox-games and in forensic fandoms for webcomics. In relying on the community, using participation and influence, Homestuck established a relationship between author and players to build a shared world that spans across the webcomic itself, official and unofficial forums, wikis, and Tumblr pages. In this sense, Homestuck is not only a comic, but an alternative nexus of communication hubs.

With the end of the webcomic series in 2016 and the closure of the official forum, an important part of this mutual world is now stuck in time. In transforming a lived experience into a stable media format (digital or printed), Homestuck itself became part of technostalgic memory. Therefore, the notion that Homestuck is "made of pure internet" (O'Malley 2012, n.p., original emphasis) does not only convey the communities it helped to build during its active run and the various digital media aspects it utilized, but also the different modes of engagement, media literacies, and expectations it relied on and satirized to tell a truthful yet funny story about coming of age in an ever more interconnected world.

\section{Notes}

1 For an introduction to comics studies and webcomics in particular, see Hammel 2016; Wilde 2015.

2 The scope of this assistance led to a six-minute-plus-long official credit video (Homestuck Official 2016). Among others, Toby Fox, who lived in Hussie's basement, made music for Homestuck. In 2015, Toby Fox released Undertale (2015), which became popular and has some similarities to Homestuck in style and atmosphere. Both Undertale and Homestuck are heavily inspired by the Japanese role paying game EarthBound (1994), as Hussie himself states in the printed version (Hussie 2011, 21).

3 For the credits, see Homestuck Official 2016. Originally, Homestuck was hosted as part of the MS Paint Adventures homepage www.mspaintadventures.com (accessed 31 January 2020). In 2018, when Viz Media acquired the rights for publishing Homestuck and www.homestuck.com (accessed 31 January 2020), also owned by Viz, it became the new official homepage for the webcomic. Before that, the first three chapters were published by the Canadian online retailer Topato Corporation (Hussie 2011; 2012a; 2013).

4 After the webcomic had ended, two game spin-offs were developed by What Pumpkin Games, initially founded in 2010 by Hussie as a record label. The first act of Hiveswap, an old-school point-and-click adventure game, was released in 
2017. The game had been a success on the crowdfunding platform Kickstarter. As Whitson and Salter note: "[Homestuck] has [...] a very strong fan following [...] and a Kickstarter campaign was funded to produce a video game around the comic's narrative. Such successes demonstrate that the addition of the web modality to the comic form can transform the core interaction of the experience" $(2015, \mathbb{S} 8)$. Even though the videogame is set in the same universe, it features different characters, mainly a human girl named Joey, who switches places with a Dammek, a troll from another planet. Hiveswap Friendsim, a series of visual novel friendship dating sims, was released in 2018 for PCs and smartphones and consisted of 18 episodes and an epilogue.

5 The reference to MS Paint was kept even though he switched to Adobe Photoshop soon after drawing the first strips in the classic graphic editor.

6 The statistics show that the busiest day consisted of 66 pages and 111 panels. But Hussie also took long hiatuses, the longest lasting for over a year (Bailey 2018).

7 For a more in-depth analysis of gender and sex in Homestuck, see Wagner 2013. Also noteworthy is McInroy and Craig's (2018) exploration of the relation between fandom participation and LGBTIQ identities.

8 Fenty, Houp, and Taylor (2005) have analyzed the relationship between Underground Comix and webcomics. They conclude that both comics formats parody popular culture, but that Underground Comix rely more on "gender relations [and] drugs" while webcomics focus on "video games, and table-top role-playing games" (Fenty et al. 2005, n.p.). In this sense, Homestuck connects those two focal points as it combines nerdy, geeky topics and discussions on gender. See also Litwhiler 2013, 20-21.

9 As Noël Carroll wrote and critiqued in "The Specificity of Media in the Arts" (1985), the notion of media specificity or media essentialism is bound to the idea that different media forms can be distinguished from each other. In this unilateral perspective, media are seen as mere technology, with certain physical properties. Carroll shifts this focus to the usage and practices of media, since media should be understood in the context of the culture surrounding them, for example, limitations, definitions, styles, and genres that shape the exception and practices of media production and reception.

10 "The platform has emerged as a new business model, capable of extracting and controlling immense amounts of data, and with this shift we have seen the rise of large monopolistic firms" (Srnicek 2017, 6). Social media platforms include Facebook, Twitter, and Instagram. Concerning the relation between platform capitalism, comics production, and reception, see Glaser 2018.

11 Other characters also use different chat clients. For example, the trolls use Trollian to troll each other. The name is probably a reference to Trillian, a software that was created in 2000 and is able to connect different instant messaging protocols in one interface. Other chat clients in Homestuck include Delirious Biznasty, Rebelgram, and BettyBotherSee. Trollian also connects different timelines of the story (Hussie 2018, 4104).

12 On the history, (problematic) definition, and culture of indie games and independent games, see Parker 2014; Sharp 2016.

13 Understood as the "representation of one medium in another" (Bolter and Grusin 1999, 45), the term remediation here draws especially on the experience of different modes of media engagement.

14 See http://ninasays.so/lostmemoriesdotnet/ (accessed 31 January 2020). 
15 Furthermore, simulated operating systems and nostalgic media usage play an important role in several other videogames. Digital: A Love Story (2010), for instance, alludes to the aesthetic and functionality of the AmigaOS Workbench and communication in Bulletin Board Systems. The interface of A Normal Lost Phone (2017) simulates that of a smartphone.

16 See also the project and blog One Terabyte of Kilobyte Age by Olia Lialina and Dragan Espenschied: https://blog.geocities.institute (accessed 31 January 2020).

17 GameFAQs is a dedicated community for people to share cheats, walkthroughs, tips, and of course FAQs for videogames. It was created in 1995 by Jeff Veasey.

18 Other examples include a later entry with screenshots (Hussie 2018, 510), an introduction to captcha codes and card alchemy (Hussie 2018, 845), and Rose's final entry: "In case it wasn't clear, magic is real" (Hussie 2018, 1942).

19 The latest post on the blog is a review on the March issue of GameBro (Hussie 2018, 325).

20 GameBro might be a reference to GamePro, a videogame magazine that was published by IDG between 1989 and 2011. GamePro is also the name of a German videogame magazine founded in 2002.

21 Examples of the webcomic can be found in Homestuck (Hussie 2018, 326, 459) and were simultaneously collected on a separate page: www.mspaintadventures. com/sweetbroandhellajeff (accessed 31 January 2020).

22 The same translation from interactive media to static images occurred in the printed version of Homestuck. Hussie describes this remediation as the difference between a game and a strategy guide: "This now somewhat resembles an old Nintendo Power strategy guide, with screenshots of the game and illustrations of the consequences of player actions" (Hussie 2012a, 11). The interactive version of those pages can still be accessed on browsers that support Flash-even though the future of those versions is unclear. See for example the Flash mini-games www.homestuck.com/story/253?fl=1 (accessed 31 January 2020) and www. homestuck.com/story/769?fl=1 (accessed 31 January 2020).

23 For the information on the "death" of the MS Paint Adventures forums, see www.reddit.com/r/homestuck/comments/do4cjj/rip_mspa_forums_20082016/ (accessed 31 January 2020).

24 One might even argue that those mini-games are not "real games" since they lack the possibility to fail. Therefore, they do not the fit the terms game comics or hypercomics as defined by Goodbrey 2015.

25 The history of GIF animations is tied to the notion of the internet as a realm of new aesthetics, beyond only technological innovations. As Jason Eppinks states: "It [the GIF] has an ethos, a utility, an evolving context, a set of aesthetics" (2014, 298). Using GIF animations therefore calls upon the idea of Homestuck being made out of and for the internet.

26 Hussie alludes to this connection in his introduction to the webcomic written for the crowdfunding campaign: "[Homestuck] heavily involves satire of internet culture, various game genres and systems, and most fundamentally, adventure games. The entire format is based on a parody of text-based and point-and-click adventure games" (Hussie 2012b, n.p.).

27 Below the command prompt, we find the last reference to videogame logic, the options to save and load the game, to toggle autosave or delete game datajavascript functions enabling the page to display us the last visited page. 
28 Rose's wardrobifier settings were determined by a poll: "The decision was tough, but you think you came to the best possible conclusion" (Hussie 2018, 800). The following link leads to an image showing the result of the poll: www.homestuck. com/images/storyfiles/hs2/scraps/poll_jadeshirt.gif (accessed 31 January 2020).

29 The leveling up system is shown as a change in numbers, title, and amount of Boondollars (Hussie 2018, 405, 555, 1891).

30 It is a long journey for John from first captchaloguing fake arms (Hussie 2018, 7) to obtaining a control deck for easier access (Hussie 2018, 964).

31 Rose retrieves her laptop, which leads to her whole item tree collapsing and spilling the other items on the ground (Hussie 2018, 236).

32 Yelling "Stop!" $(2+2+1+2)$ accidentally releases a ninja sword (Hussie 2018, 354).

33 After connecting to Sburb (Hussie 2018, 114), server players can create new objects-this possibility sometimes results in Escher-like buildings (Hussie 2018, 1081).

34 Hussie also refers to this in the paratext: "I believe the false menus like this actually felt quite convincing, and sort of activated the game-playing center of the reader's brain, making them want to use these tools, and on some level, causing them to actually believe they can" (Hussie 2011, 80).

\section{Works cited}

Adobe Corporate Communications. 2017. "Flash and the Future of Interactive Content.” Adobe Blog, 25 July. http://theblog.adobe.com/adobe-flash-update (accessed 31 January 2020).

Bailey, Anthony. 2018. MS Paint Adventures: Statistics. http://readmspa.org/stats (accessed 31 January 2020).

Bolin, Göran. 2016. "Passion and Nostalgia in Generational Media Experiences." European Journal of Cultural Studies 19 (3): 250-264.

Bolter, J. David, and Richard Grusin. 1999. Remediation: Understanding New Media. Cambridge, MA: MIT Press.

Carroll, Noël. 1985. "The Specificity of Media in the Arts." Journal of Aesthetic Education 19 (4): 5-20.

Chartrand, Roxanne, and Pascale Thériault. 2018. "The Videoludic Cyborg: Queer/ Feminist Reappropriations and Hybridity." Proceedings of The Philosophy of Computer Games Conference 2018: n.p. https:/gameconference.itu.dk/papers/ $15 \% 20-\% 20$ chartrand \%20-\%20the\%20videoludic\%20cyborg.pdf (accessed 31 January 2020).

Chute, Hillary, and Patrick Jagoda. 2014. "Introduction: Special Issue: Comics and Media.” Critical Inquiry 40 (3): 1-10.

Cibele. 2015. Developed and published by Star Maid Games and Nina Freeman. Windows.

Couture, Joel. 2018. "What Makes a Great Idle Animation? Devs Share Their Favorites.” Gamasutra, 21 May. www.gamasutra.com/view/news/318163/what_ makes_a_great_idle_animation_devs_share_their_favorites.php (accessed 31 January 2020).

Digital: A Love Story. 2010. Developed and published by Love Conquers All Games. Windows.

EarthBound. 1994. Developed by Ape and HAL Laboratory. Published by Nintendo. SNES. 
Emily Is Away. 2015. Developed and published by Kyle Seeley. Windows.

Eppink, Jason. 2014. "A Brief History of the GIF (So Far)." Journal of Visual Culture 13 (3): 298-306.

Fenty, Sean, Trena Houp, and Laurie N. Taylor. 2005. "Webcomics: The Influence and Continuation of the Comix Revolution" ImageTexT: Interdisciplinary Comics Studies 1 (2): n.p. http://imagetext.english.ufl.edu/archives/v1_2/group/ (accessed 31 January 2020).

Galloway, Alexander R. 2006. Gaming: Essays on Algorithmic Culture. Minneapolis: University of Minnesota Press.

Glaser, Tim. 2018. "oh no-this comic is literally me: Webcomics im Zeitalter ihrer memetischen Rezeption." CLOSURE: Kieler e-Journal für Comicforschung 4.5: n.p. www.closure.uni-kiel.de/closure4.5/glaser (accessed 31 January 2020).

Goodbrey, Daniel Merlin. 2015. "Game Comics: An Analysis of an Emergent Hybrid Form." Journal of Graphic Novels and Comics 6 (1): 3-14.

Hammel, Björn. 2016. "Webcomics." In Comics und Graphic Novels: Eine Einführung, edited by Julia Abel and Christian Klein, 169-180. Stuttgart: Metzler.

Hiveswap: Act 1. 2017. Developed by What Pumpkin Games. Published by Fellow Traveller. Windows.

Hiveswap Friendsim: Volume 1 to 18. 2018. Developed by What Pumpkin Games. Published by Fellow Traveller. Windows.

Homestuck Official. 2016. "Credits." YouTube, 24 October. www.youtube.com/ watch?v=rMZU89jY2j8 (accessed 31 January 2020).

Hussie, Andrew. 2011. Homestuck Book One. Easthampton: Topatoco.

Hussie, Andrew. 2012a. Homestuck Book Two. Easthampton: Topatoco.

Hussie, Andrew. 2012b. "What Is Homestuck?" MS Paint Adventures, n.d. http:// mspaintadventures.com/scraps2/homestuckKS.html (accessed 31 January 2020).

Hussie, Andrew. 2013. Homestuck Book Three. Easthampton: Topatoco.

Hussie, Andrew. 2014. "Answers (Archive).” MS Paint Adventures Wiki Blog, n.d. http://mspaintadventureswiki.tumblr.com/post/63803326538/answers-archive (accessed 31 January 2020).

Hussie, Andrew. 2018. Homestuck. www.homestuck.com (accessed 31 January 2020).

Lialina, Olia. 2015. A Vernacular Web. http://art.teleportacia.org/observation/ vernacular/ (accessed 31 January 2020).

Litwhiler, Austin Gunner. 2013. "From Pulp to Webpage: Homestuck and Postmodern Digital Narrative.” Honors thesis, State University of New York at Albany, US. https://scholarsarchive.library.albany.edu/honorscollege_eng/13/ (accessed 31 January 2020).

Lost Memories Dot Net. 2017. Developed and published by Nina Freeman and Aaron Freedman. Windows.

McInroy, Lauren B., and Shelly L. Craig. 2018. "Online Fandom: Identity Milestones, and Self-Identification of Sexual/Gender Minority Youth.” Journal of LGBT Youth 15 (3): 1-18.

Mittell, Jason. 2007. “Lost in a Great Story.” Just TV (blog), 23 October. http://justtv. wordpress.com/2007/10/23/lost-in-a-great-story (accessed 31 January 2020).

Muncy, Julie. 2015. "Return to the 2000s with This AIM-Inspired Chat Game." Wired, 30 October. www.wired.com/2015/10/emily-is-away (accessed 31 January 2020). 


\section{T. Glaser}

A Normal Lost Phone. 2017. Developed by Accidental Queens. Published by Plug in Digital. Windows.

O’Malley, Bryan Lee. 2012. “'Scott Pilgrim' Guy Interviews 'Homestuck' Guy: Bryan Lee O’Malley on Andrew Hussie.” ComicsAlliance, 2 October. http:// comicsalliance.com/homestuck-interview-andrew-hussie-bryan-lee-omalley-mspaint-adventures (accessed 31 January 2020).

Parker, Felan. 2014. "Indie Game Studies Year Eleven.” Proceedings of DiGRA 2013: DeFragging Game Studies: n.p. www.digra.org/digital-library/publications/ indie-game-studies-year-eleven/ (accessed 31 January 2020).

Paul, Christopher A. 2018. The Toxic Meritocracy of Video Games. Minneapolis: University of Minnesota Press.

PBS Idea Channel. 2012. "Is Homestuck the Ulysses of the Internet? I Idea Channel I PBS Digital Studios." YouTube, 5 September. www.youtube.com/ watch?v=MLK7RI_HW-E (accessed 31 January 2020).

Sharp, John. 2016. “Independent Games.” In Debugging Game History: A Critical Lexicon, edited by Henry Lowood and Raiford Guins, 259-267. Cambridge, MA: MIT Press.

Short, Jennifer. 2014. "Let Me Tell You about Homestuck: The Online Production of Place.” Master thesis, University of Central Florida, US. https://stars.library.ucf. edu/etd/4806/ (accessed 31 January 2020).

The Sims. 2000. Developed by Maxis. Published by Electronic Arts. Windows.

Srnicek, Nick. 2017. Platform Capitalism. Cambridge: Polity Press.

Undertale. 2015. Developed and published by Toby Fox. Windows.

Veale, Kevin. 2019. “'Friendship Isn't an Emotion Fucknuts': Manipulating Affective Materiality to Shape the Experience of Homestuck's Story." Convergence: The International Journal of Research into New Media Technologies 25 (5-6): 1027-1043.

Wagner, Jamie. 2013. "The Webcomic Homestuck as Gender Fiction and Its Discourse on Gender Issues in the Narrative.” Term paper, University of Konstanz, Germany.

Whitson, Roger Todd, and Anastasia Salter. 2015. "Introduction: Comics and the Digital Humanities.” Digital Humanities Quarterly 9 (4): n.p. http:// digitalhumanities.org/dhq/vol/9/4/000210/000210.html (accessed 31 January 2020).

Wilde, Lukas R. A. 2015. "Gibt es eine Ästhetik des Webcomic?” In Webcomic im Fokus: Internationaler Comic-Salon Erlangen 2014, edited by Lukas R. A. Wilde and Comic Solidarity, 4-15. Self-published. 